\title{
Dexamethasone as an Adjuvant in the Axillary Echoguided Block: Prospective Single-Blind, Non-Randomized Study
}

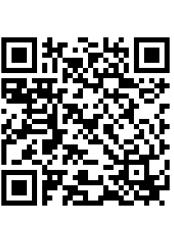

\begin{abstract}
Mamadou Mour TRAORE ${ }^{2 *}$, Papa Alassane LEYE ${ }^{1}$, Elvire DOUSSOUMOU ${ }^{1}$, Mamadou Diawo BAH ${ }^{3}$, El Boubacar BA ${ }^{3}$, Ibrahima GAYE ${ }^{1}$, Marie Diop NDOYE ${ }^{2}$, Mamadou Diarrah BEYE ${ }^{1}$, Elisabeth DIOUF ${ }^{1}$
\end{abstract}

${ }^{1}$ Department of Anesthesia \& Intensive Care, University Hospital Aristide Le Dantec, Africa

${ }^{2}$ Department of Pediatric Anesthesia, Unit of Children Hospital, Africa

${ }^{3}$ University National Hospital of Fann, Africa

Submission: July 22, 2019; Published: August 08, 2019

*Corresponding author: Mamadou Mour TRAORE, Pediatric Anesthesia, Unit of Children Hospital, Albert Royer, Dakar, Africa

Abstract

Background : Dexamethasone has been used for some years as an adjunct to local anesthetics in peripheral nerve blocks. Recently studies suggest its effectiveness in prolonging the duration of postoperative analgesia. The primary objective of this study was to evaluate the efficacy of dexamethasone as adjuvant in the axillary ultrasound guided block.

Methods: Adults who required upper limb surgery in a scheduled or emergency mode were prospectively divided into two groups of 30 patients. An axillary block under ultrasound guidance was performed with an equimolar mixture of lidocaine $2 \%-0.5 \%$ bupivacaine associated with dexamethasone in the dexamethasone group and without dexamethasone in the control group. The evaluation of the block was done by a blind operator of the block technique. All the parameters of the nerve block as well as the delay of the demand in analgesic were noted. The study was analyzed per protocol.

Results: A total of sixty patients were grouped into two equitable groups. Demographic parameters were similar between two groups. The duration and the time of installation of the axillary block were respectively $13.76 \mathrm{~min}(7-30)$ for the control group against 12.76 min (5-20) for the dexamethasone group $(\mathrm{p}=0.27)$ and $11.36 \mathrm{~min}(5-30)$ for the control group $11.66(5-30)$ for the dexamethasone group $(\mathrm{p}=0.81)$. The duration of sensory block was extended in the dexamethasone group by about $56 \%$ compared to the control group. The motor block was also $21.5 \%$ longer in the dexamethasone group. The delay in the use of analgesics was significantly longer in the dexamethasone group with better EVS scores compared to the control group. Plexus neuropathy was found postoperatively.

Conclusion: The use of dexamethasone as an adjuvant in the axillary block prolongs postoperative analgesia in a clinically significant manner and also leads to a decrease in analgesic consumption.

Keywords: postoperative analgesia; axillary ultrasound-guided block; perineural dexamethasone; lidocaine-bupivacaine

\section{Introduction}

The management of postoperative pain that predominates for the first 48 hours after surgery remains a real therapeutic issue [1]. Its intensity and duration are known risk factors for chronic pain [1], justifying prolonged analgesia. Perineural locoregional anesthesia (Pn-LRA) is a technique of choice in orthopedic surgery, which guarantees quality anesthesia and postoperative analgesia [2]. The practice of locoregional anesthesia (LRA) is recommended by the SFAR in 2016 as the only technique of anesthesia in the surgery of the upper limb [3], because of a better analgesic efficacy with a significant reduction in the consumption of opioids. Thus, in view of prolonged analgesia in the first 24 hours after surgery, some teams prefer to use an adjuvant in relation to the insertion of a peri-neural catheter. Dexamethasone (DTX) to date has demonstrated its ability to achieve this goal [4] however it is used in different dosages depending on the team. The aim of this article is to evaluate the efficacy of dexamethasone as an 
adjuvant to the $4 \mathrm{mg}$ perineural dose associated with bupivacain in the axillary echoguided block.

\section{Methods}

A prospective, non-randomized, double-blind study during a period of 10 months from November 2017 to August 2018 was conducted in the central operating theater of Aristide le Dantec Teaching Hospital in Dakar.

Patients included in this study were adults requiring upper limb surgery, with or without tourniquet, in scheduled surgery or in emergency. The criteria for non-inclusion are contraindications of peripheral LRA, patient refusal, local infection of the ponction site, progressive peripheral neurological disorders, coagulation disorders, failures of block.

\section{Anesthetic protocol}

All patients had benefited from a peripheral intra-venous. Monitoring was provided by ECG tracing, heart rate (HR), noninvasive pressure (NIP), and oxygen saturation (SPO2).

Venous premedication was carried out with diazepam (3mg) before blocking in patients according to their degree of cooperation. The patient was supine, the traumatized limb to be blocked was abducted at $90^{\circ}$, the elbow bent or not, and the supine hand.

Patients were divided into two groups arbitrarily. A Cintrol group consisting of 30 patients who received a axillary block (BAX) with lidocain $2 \%$ bupivacain $0.5 \%$ at fifhty-fifthty and a second group DTX also comprising 30 patients benefiting from the same block with dexamethasone $4 \mathrm{mg}$.

\section{Axillary block technique}

The axillary block was performed with a $100 \mathrm{~mm}$ short bevel stimuplex A needle, connected or not to the sentinel neurostimulator of $0.3 \mathrm{~mA}$. After skin disinfection, the probe is positioned in the axillary hollow transversely to the vasculonervous axis, an ultrasound identification of the axilla and arm to identify the different structures. The approach of the plexus was either in the plane (IP) or out of the plane (OP) made from the small axis of the ultrasound probe. The needle was then inserted above and below the artery, the local anesthetic was injected peri-nervously, around each identified nerve structure after identification of the nerve. The injection of the anesthetic product was done under ultrasound control. For patients in control group, a slow injection of $28 \mathrm{ml}$ (equivalent of $6 \mathrm{ml}$ per nerve $+4 \mathrm{ml}$ for infiltration of the medial cutaneous arm and forearm). On the other hand for the patients of the DTX group , the same added volume of $4 \mathrm{mg}$ of dexamethasone was injected. The safety aspiration tests at each $4 \mathrm{ml}$ were respected in both groups.

\section{Block Evaluation}

This evaluation was conducted by an outside medical person blind to the block technique. The patient had no information about the use or not of dexamethasone. The sensory block was assessed by cold test with an ice cube, on different nervous territories of the upper limb. The quality of the sensory block was evaluated over an interval of 5 to $30 \mathrm{~min}$. the sensory block was considered satisfactory in the absence of perception of cold on the different territories concerning the surgical incision. The motor block was evaluated at $30 \mathrm{~min}$ by voluntary mobilization, and rated as a complete motor block or incomplete motor block. The sensory and motor blocks were appreciated at intervals of four hours until the first pain apparition.

The primary outcome was the duration of the sensory block. This is defined by the time measured between the removal of the puncture needle at the onset of the first painful sensations. SVS (Simple Verbal Scale) was used to rate pain.

The secondary outcome consisted in the consumption of analgesics postoperatively the incidence of complications.

We carried out per protocol analysis. The variables in this study are expressed as percentage and standard deviation. The software used was EPI info version 7.2.2.16.

\section{Results}

A total of sixty patients was enrolled. As regards the demographic characteristics (Table 1), there was no significant differences in the mea nage, BMI, ASA class of the patients and the duration of surgery in the group.

Table 1: Demographic and Surgical Characteristics.

\begin{tabular}{|c|c|c|c|}
\hline & Control Group & DTX Group & P-Value \\
\hline Age (year) & $35,76(22-60)$ & $36(19-75)$ & 0,94 \\
\hline Gender (M/F) & $24 / 6$ & $22 / 8$ & 0,76 \\
\hline BMI (kg/m2) & $26,09(17,30-31,25)$ & $24,58(21,24-31,25)$ & 0,03 \\
\hline ASA $1 / 2 / 3$ & $21 / 9 / 0$ & $25 / 4 / 1$ & 0,20 \\
\hline \multicolumn{2}{|c|}{ Type of Surgery } & \multirow{2}{*}{$1 / 19 / 10$} & \multirow{2}{*}{0,18} \\
\hline Arm/ Upper-arm / Hand & $1 / 20 / 9$ & & \\
\hline Duration of surgery (min) & $93,56(45-210)$ & $91,83(60-220)$ & 0,06 \\
\hline Approach IP/OP+IP & $25 / 5$ & $23 / 7$ & 0,78 \\
\hline Time of achievement (min) & $13,76(7-30)$ & $2,33(5-20)$ & 0,27 \\
\hline
\end{tabular}


Journal of Anesthesia \& Intensive Care Medicine

\begin{tabular}{|c|c|c|c|}
\hline Installation delay (min) & $11,36(5-30)$ & $11,66(5-30)$ & 0,81 \\
\hline Duration of sensory block (min) & $274,1(160-420)$ & $426,8(240-1200)$ & 0,00 \\
\hline Complete motor block (n) & $56,67 \%$ & $83,33 \%$ & 0,00 \\
\hline Duration of motor block (min) & $182,5(90-300)$ & $221,8(120-360)$ & 0,00 \\
\hline
\end{tabular}

IP: In the plane; OP: Out of the plane; BMI: Body Mass Index.

\section{The delay of the request for postoperative analgesic}

Patients in the DTX group had longer postoperative analgesia duration $(\mathrm{p}=0.00)$ than patients in the control group with a significantly longer analgesic application time (Figure 1).

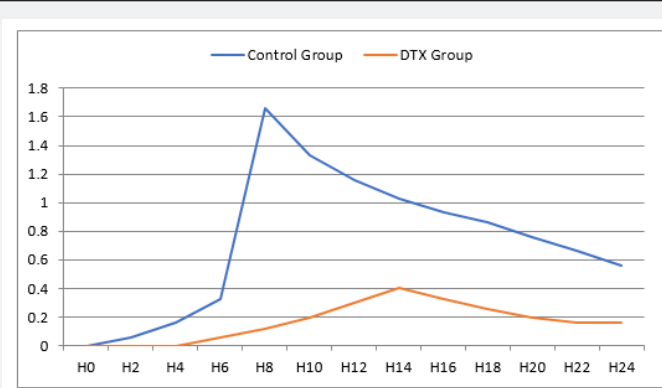

Figure 1: Change in Simple verbal Scale in 2 groups.

A complication in a patient with a plexus lesion in the axillary fossa involving the ulnar nerve, the radial nerve and the circumflex nerve. No other side effects was reported during the first 24 hours groups.

\section{The experience of the anesthesiologist}

All the blocks were stung by resident in training under the supervision of a senior anesthesiologist.

\section{Discussion}

The results of this study confirm the efficacy of dexamethasone in prolonging the analgesic effect of bupivacain in the axillary block for upper limb surgery. Thus our investigation finds the result of several previous studies [5-7]. However, in these previous studies the results are variable ranging from 30 to $80 \%$ any route of administration confused, peri or intravenous. In a work on the interscalene block, Viera et al. [4] showed that the addition of 8mg of dexamethasone to a mixture of $20 \mathrm{mg}$ of bupivacain concentrated at $5 \mathrm{mg} / \mathrm{ml}$, of adrenaline at $1 / 200000$ and of clonidine at $75 \mu \mathrm{g}$, allowed a net increase of the duration of the sensory block [4]. Indeed, the duration of the sensory block was prolonged more than 24 hours in patients who received dexamethasone against 13 hours in the group without dexamethasone. The motor block was also prolonged about 23 hours in the dexamethasone group against 13 hours in the control group whereas in our study the motor block was prolonged by $21 \%$. In the work of Viera et al, the symbolic course of the 24 hours of analgesia was passed with however a combination of 4 agents which is not without inconvenience and can appear as difficult to recommend in routine because of the multiplication of fault risks.
Studies using doses similar to ours were performed by perineural administration [8]. Thus, Tandoc et al have proved during the realization of an interscalene block that a dose of $4 \mathrm{mg}$ of dexamethasone provided a duration of action comparable to that obtained with a dose of $8 \mathrm{mg}$, when it was associated with $40 \mathrm{ml}$ of bupivacain at $5 \mathrm{mg} / \mathrm{ml}$. It was $21.6+/-2.4$ hours in the group who received $4 \mathrm{mg}$ dexamethasone versus $25.2+/-1$.9hours in the group who received $8 \mathrm{mg}$. While the duration of analgesia was only $13.3+/-1.0$ hours in the group in which only bupivacain was administered. The quality of the engine block (complete/ incomplete) has not been discussed in most previous studies. In our study, the statistically significant difference $(\mathrm{P}=0.00)$ between the two groups concerning the motor block, allows us to affirm that dexamethasone improves the quality of the motor block [5] (study score engine block). We note in our study that the average time required for post-operative analgesics was significantly increased $(\mathrm{P}=0.000)$ in favor of the dexamethasone group. This mean delay was $854.831 \mathrm{~min}$ in the dexamethasone group versus $332 \mathrm{~min}$ in the dexamethasone-treated group. By extending the duration of sensory blocking, dexamethasone provides significant analgesia. It also allows a significant decrease in the consumption of analgesic reported in many series of the literature. In this clinical trial the evolution of the postoperative pain scores of both groups clearly illustrates the decrease in scores in favor of the dexamethasone group. In this sense dexamethasone decreases the consumption of opioids as found in several clinical trials [911].

One of the biggest questions raised about the use of dexamethasone in locoregional anesthesia is related to its safety and the potential risk of neurotoxicity is currently a controversial issue. Several experimental studies have shown potentiation of the neurotoxicity of local anesthetics associated with certain adjuvants such as clonidine, midazolam, buprenorphine or even dexamethasone. Williams et al in their work on mouse nerve cells have shown that these adjuvants used alone are less toxic than local anesthetics in contact with the nerve cell [12]. In our study only one case of nerve toxicity documented by EMG was found. Its multi-radicular character affecting three nerves (ulnar, circumflex and radial) seems more to be attributable to a product toxicity than a nerve puncture injury. Regarding the safety of dexamethasone several clinical studies have evaluated the incidence of neurological complications related to its perineural administration $[13,14]$. No nerve damage has been found in this work. Thus, faced with the limits of the use of dexamethasone perineural, some authors have considered its intravenous use in search of a significant prolongation of the duration of action of 
local anesthetics in a peripheral nervous block. Thus, Desmet et al showed that the effect produced by $10 \mathrm{mg}$ of dexamethasone administered intravenously at the beginning of the intervention was comparable to that obtained with peri-neural dexamethasone in terms of prolongation of the analgesic duration [13]. However, data from the literature on equivalent doses of peri-neural and intravenous dexamethasone are discordant.

Our study has a number of limitations related to its nonrandomized double blindness but also to its lack of power to conclude on the safety of dexamethasone. Subsequent clinical trials with sufficient power will make it possible to have a clear idea of the complications related to the use of peri-neural dexamethasone before a systematic recommendation for the management of postoperative pain as a major issue in our profession.

\section{Conclusion}

Like most previous studies, our clinical trial confirms the efficacy of peri-neural dexamethasone to prolong analgesic duration. Today, the anesthetic has this non-negligible advantage for the daily management of postoperative pain. At present, dexamethasone has not shown in human medicine actual toxicity or more than routine adjuvants such as clonidine. To circumvent possible direct neural toxicity, dexamethasone may be administered intravenously however the effect seems to be less compared to the péri-neural route. Rigorous prospective comparative and controlled studies will be needed to confirm the equivalence of intravenous and peri-neural doses.

\section{References}

1. Kehlet H, Jensen TS, Woolf CJ (2006) Persistent surgical pain: risk factors and prevention. Lancet 367(9522): 1618-1625.

2. Ullah H, Samad K, Khan FA (2014) Continuous interscalene brachial plexus block versus parenteral analgesia for postoperative pain relief after major shoulder surgery. Cochrane Database Syst Rev 4(2): CD007080.

3. Référentiels Formatisés d'Expert (RFE) (2016) de la Société Francaise d'Anesthésie Réanimation Alr périnerveuse.
4. Vieira PA, Pulai I, Tsao GC, Manikantan P, Keller B, et al. (2010) Dexamethasone with bupivacaine increases duration of analgesia in ultrasound-guided interscalene brachial plexus blockade. Eur J Anaesthesiol 27(3): 285-288.

5. Movafegh A, Razazian M, hajimaohamadi F, Meysamie A (2006) Dexamethasone added to lidocaine prolongs axillary brachial plexus blockade. Anesth Analg 102(1): 263-267.

6. Parrington SJ, O'Donnell D, Chan VW, Brown-Shreves D, Subramanyam $\mathrm{R}$, et al. (2010) Dexamethasone added to mepivacaine prolongs the duration of analgesia after supraclavicular brachial plexus blockade. Reg Anesth Pain Med 35(5): 422-426.

7. Ibrahim AS, Aly MG, Farrag WS, Gad El Rab NA, Said HG, et al. (2019) Ultrasound-guided adductor canal block after arthroscopic anterior cruciate ligamentre construction: Effect of adding dexamethasone to bupivacaine, a randomized controlled trial. Eur J Pain 23(1): 135-141.

8. Tandoc MN, Fan L, Kolesnikov S, Kruglov A, Nader ND (2011) Adju-vant dexamethasone with bupivacaine prolongs the duration of interscalene block: a prospective randomized trial. J Anesth 25(5): 704-709.

9. Bindal D, Narang N, Mahindra R, Gupta H, Kubre J, et al. (2018) Effect of Dexamethasone on Characteristics of Supraclavicular Nerve Block with Bupivacaine and Ropivacaine: A Prospective, Double-blind, Randomized Control Trial. Anesth Essays Res 12(1): 234-239.

10. Hauritz RW, Hannig KE, Henriksen CW, Borglum J, Bjorn S, et al. (2018) The effect of perineural dexamethasone on duration of sciatic nerve blockade: a randomized, double-blind study. Acta Anaesthesiol Scand 62(4): 548-557.

11. Mum Huynh T, Marret E, Bonnet F (2012) Dexaméthasone et bloc nerveux périphérique : Méta-analyse d'essais randomisés. Résumé R01, SFAR, Paris,

12. Williams BA, Hough KA, Tsui BY, Ibinson JW, Gold MS, et al. (2011) Neurotoxicity of adjuvants used in perineural anesthesia and analgesia in comparison with ropivacaine. Reg Anesth Pain Med 36(3): 225-230.

13. Desmet M, Braems H, Reynvoet M, Plasschaert S, Van Cauwelaert J, et al. (2013) I.V. and perineural dexamethasone are equivalent in increasing the analgesic duration of a single- shot interscalene block with ropivacaine for shoulder surgery: a prospective, randomized, placebo-controlled study. Br J Anaesth 111(3): 445-452.

14. Cummings KC 3rd, Napierkowski DE, Parra-Sanchez I, Kurz A, Dalton JE, et al. (2011) Effect of dexamethasone on the duration of interscalene nerve blocks with ropivacaine or bupivacaine. Br J Anaesth 107(3): 446-453.

\section{Your next submission with Juniper Publishers will reach you the below assets}

- Quality Editorial service

- Swift Peer Review

- Reprints availability

- E-prints Service

- Manuscript Podcast for convenient understanding

- Global attainment for your research

- Manuscript accessibility in different formats

( Pdf, E-pub, Full Text, Audio)

- Unceasing customer service

Track the below URL for one-step submission https://juniperpublishers.com/online-submission.php 